\title{
Genetic analysis of medfly populations in an area of sterile insect technique applications
}

\author{
Rubén Sancho $^{1}\left[\right.$ - Ana Guillem-Amat ${ }^{1}\left[\right.$ - Elena López-Errasquín ${ }^{1} \cdot$ Lucas Sánchez $^{2} \cdot$ Félix Ortego $^{1}$. \\ Pedro Hernández-Crespo ${ }^{1}$
}

Received: 10 July 2020 / Revised: 15 December 2020 / Accepted: 24 December 2020 / Published online: 10 February 2021

(C) The Author(s) 2021

\begin{abstract}
The sterile insect technique (SIT) is widely used in integrated pest management programs for the control of the Mediterranean fruit fly (medfly), Ceratitis capitata. The genetic interactions between the released individuals from the genetic sexing strains (GSS), used for SIT applications worldwide, and wild individuals have not been studied. Under the hypothesis that a number of Vienna GSS individuals released to the field might not be completely sterile and may produce viable offspring, we have analyzed medfly Spanish field populations to evaluate the presence of Vienna strain genetic markers. To this goal, we have used contrasted nuclear and mitochondrial genetic markers, and two novel sets of nuclear polymorphisms with the potential to be markers to discriminate between Vienna and wild individuals. Nuclear Vienna markers located on the 5th chromosome of Vienna males have been found in 2.2\% (19 from 875) of the Spanish wild medfly females captured at the area where SIT is applied. In addition, a female-inherited mitochondrial Vienna marker has been found in two from the 19 females showing nuclear Vienna markers. The detection of several of these markers in single individuals represents evidence of the introgression of Vienna strain into natural populations. However, alternative explanations as their presence at low frequency in wild populations in the studied areas cannot be fully discarded. The undesired release of non-fully sterile irradiated GSS individuals into the field and their interactions with wild flies, and the potential environmental implications should be taken into account in the application of the SIT.
\end{abstract}

Keywords Genetic markers $\cdot$ Sterile insect technique $\cdot$ Tephritids $\cdot$ Medfly $\cdot$ Vienna strain

Communicated by Christian Stauffer.

Pedro Hernández-Crespo

pedro@cib.csic.es

Rubén Sancho

ruben.sancho.cohen@gmail.com

Ana Guillem-Amat

anaguiam@gmail.com

Elena López-Errasquín

elena.lopez@cib.csic.es

Lucas Sánchez

1sanchez@cib.csic.es

Félix Ortego

ortego@cib.csic.es

1 Departamento de Biotecnología Microbiana y de Plantas, Centro de Investigaciones Biológicas Margarita Salas, CSIC, Madrid, Spain

2 Departamento de Biología Celular y Molecular, Centro de Investigaciones Biológicas Margarita Salas, CSIC, Madrid, Spain

\section{Key message}

- Medfly populations have been analyzed in an area of sterile insect technique (SIT) applications.

- Novel selected and available Vienna nuclear and mitochondrial markers have been analyzed.

- Vienna markers have been identified in wild females from an area of SIT applications.

- Our results provide evidence of the introgression of Vienna strain into natural populations.

- The presence of Vienna markers at low frequency in wild populations is also considered. 


\section{Introduction}

The Mediterranean fruit fly (medfly) Ceratitis capitata (Wiedemann) (Diptera: Tephritidae) is a polyphagous and worldwide distributed insect with a high adaptive capacity. The direct damages produced in fruits and vegetables and the indirect damage resulting from the restrictions to exports in regions where medfly is established make this species an economically important agricultural pest (Liquido et al. 1990; Malacrida et al. 2007; EPPO 2020). Multiple approaches and techniques have been developed and applied for medfly control, but current control practices rely mainly on the use of insecticides. Organophosphates, such as malathion, were used during the 1990s and 2000s in Spain (Primo-Millo et al. 2003). Spinosad and two pyrethroids (lambda-cyhalothrin and deltamethrin) are currently widely used in citrus crops (Ministerio de Agricultura Pesca y Alimentación 2020). However, the development of field resistance to malathion (Magaña et al. 2007) and lambda-cyhalothrin (Arouri et al. 2015) and the recent detection of spinosad resistance alleles in field populations (Guillem-Amat et al. 2020) are raising new challenges in medfly control. In the current situation, combining different pest control approaches and boosting biologically based methods in the context of an integrated pest management (IPM) is highly recommended.

The sterile insect technique (SIT) (Knipling 1955) is considered the most target-specific and non-disruptive approach among the biologically based methods for tephritid fruit flies control (Enkerlin 2005). This technique is applied broadly for prevention, suppression or eradication of medfly (Hendrichs et al. 2002) and involves the mass rearing, sterilization and release of large quantities of sterile males that compete with wild males for mating with wild females, resulting in the reduction in wild populations. The first large medfly SIT program was implemented in Mexico in 1977, and since 1990s different programs have been applied worldwide (Hendrichs et al. 2002 and references therein). In Spain, in the late 1960s to early 1970s, preliminary small-scale studies were carried out to check the effectiveness of SIT in medfly control, showing satisfactory results in small isolated areas (Mellado et al. 1975). A large-scale pilot program was initiated in the Comunitat Valenciana in 2003-2005, with the importation of sterile males from a fly production facility located in Mendoza (Argentina) (Primo-Millo et al. 2003; Argilés and Tejedo-Tormo 2007). A factory of GSS medflies was built in Caudete de las Fuentes (Comunitat Valenciana, Spain) that has been operational since 2007. At present, 250-300 million medfly sterile males are released per week to cover a surface of 140,000 hectares (Generalitat Valenciana 2016).
Two key technological advances have allowed the implementation of the SIT programs, the development of genetic sexing strains (GSS) (Fisher 2000; Robinson 2002; Caceres et al. 2004; Parker 2005) and the establishment of filter rearing systems (FRS) at the mass-rearing facilities (Caceres 2002), allowing the massive production of male-only progeny. The GSS of medfly used in SIT programs are called Vienna strains (e.g., Vienna-7, Vienna-8), developed at the FAO/IAEA Insect Pest Control Laboratory (IPCL) in Seibersdorf, Austria. Those strains show two characteristic mutations on the fifth chromosome called $t s l$ (temperature-sensitive lethal) (Busch-Petersen 1990) and $w p$ (white pupae) (Rössler 1979). The $w p$ and $t s l$ homozygous loci produce white pupae phenotype and individuals that die under temperatures higher than $33{ }^{\circ} \mathrm{C}$ for $24 \mathrm{~h}$ during the embryonic stage, respectively. This approach is used to remove Vienna females, which are homozygous for $t s l$ and $w p$ recessive mutations and preserve Vienna males, which are heterozygous and show wild-type phenotype. Those recessive mutations, despite being located on an autosome, are sex-specific through a reciprocal translocation between the carrier region of $t s l$ and $w p$ mutations, placed on the fifth chromosome, and the male sex-specific Y chromosome (Kerremans and Franz 1994, 1995; Franz 2002, 2005). However, problems of genetic stability can take place during the mass rearing of GSS, especially as a consequence of the type 1 male recombination, consisting of the autosomal recombination in male heterozygous for the selectable marker(s). The type 2 male recombination, which occurs between the two translocated $\mathrm{Y}$ fragments, is very rare, but it can generate males with free untranslocated $\mathrm{Y}$ chromosomes that are homozygous for $w p$ and $t s l$ (Franz 2002, 2005). To reduce the presence of recombinant flies, FRS are implemented at the rearing facilities by maintaining a small standby line of a medfly strain, where recombinants are filtered out, before they accumulate in the next steps of the production (Caceres 2002). In addition, the translocation can be combined with a chromosomal inversion (e.g., Vienna- $8^{\mathrm{D} 53+}$ strain) to suppress recombination between the selectable markers and the translocation breakpoint and improve the genetic stability of the GSS (Franz 2005).

Currently, the most common sterilization technique in medfly SIT programs is by gamma radiation using doses between 90 and 145 Gy applied during the late pupal stage, 1 or 2 days prior to adult emergence (Bakri et al. 2005). These irradiation doses have been selected for inducing male sterility without compromising male performance and mating competitiveness (Sayed 2013). However, studies on effective sterilization showed that fertile females mated with Vienna males irradiated between 100-140 Gy produced eggs whose hatch rate was $<2 \%$ (Sayed 2013; Ramírez-Santos et al. 2017). Therefore, residual fertility could be present in the GSS males released. In addition, despite the continuous progress to improve the 
accuracy of female removal (Franz 2005), GSS are not 100\% stable, and some females can be occasionally released. This is especially relevant in the case of the GSS in which the D53 inversion that prevent recombination has not been introduced (e.g., Vienna- $8^{\text {D53- }}$ strain, as those released in the Generalitat Valenciana in Spain) (Franz 2005; Ramírez-Santos et al. 2017). Medfly females are also sterilized by gamma radiation and the irradiation dose required for female sterility is low compared to the dose needed for male sterilization (RamírezSantos et al. 2017); thus, the release of irradiated GSS females with residual fertility can be considered as highly unlikely. Nonetheless, considering the large quantities of males released in the areas where SIT programs are applied, their residual fertility and the possibility that recombination events take place, a genetic transferring (introgression) from GSS into wild populations could be possible.

Since the random mutations generated as a consequence of sterilization techniques might be integrated in wild populations, it is necessary to study whether introgression events are taking place and, if so, to evaluate how those events may affect the genetics of wild populations. Genetic markers to discriminate between Vienna and wild-type flies have been selected to assess mating success, Vienna recaptures and movements between populations in SIT areas. Thus, mitochondrial genetic markers were selected to distinguish Vienna and wild-type haplotypes (Gasparich et al. 1995; Spanos et al. 2000; Lanzavecchia et al. 2008; Barr 2009; Parubrub et al. 2015) and detect the presence of sterile male sperm in the female to assess mating success (San Andrés et al. 2007). In addition, one nuclear genetic marker, a single-nucleotide polymorphism (SNP), has been recently selected to distinguish between Vienna and wildtype flies (Sim et al. 2017). However, considering that a fullconfidence Vienna genetic marker does not exist, since none of them have been tested for all the potential polymorphisms found among field populations, the use of several Vienna markers that complement each other could be a suitable strategy to identify introgressed individuals.

In this study, we have genetically analyzed medfly populations from the Comunitat Valenciana, an area where a SIT program is applied on a large-scale since 2007, to search for the presence of genetic markers for Vienna GSS. To achieve this goal, we have combined available nuclear (Sim et al. 2017) and mitochondrial (Gasparich et al. 1995; Spanos et al. 2000; San Andrés et al. 2007) Vienna genetic markers with two novel set of nuclear polymorphisms with the potential to discriminate between Vienna and wild individuals.

\section{Material and methods}

\section{In silico analyses}

RNA-Seq datasets from Vienna strain and a Hawaiian wild population (Calla et al. 2014), as well as our own sequencing (BAM files are available in the European Nucleotide Archive (ENA): ERR4690325, ERR4690326 and ERR4690327) on the C strain (Magaña et al. 2007), were analyzed in silico to select coding regions candidates to be Vienna markers (Online Resource 1). Sequences of Vienna adults and pupae irradiated (adults: SRR915830, SRR915831, SRR915832; pupae: SRR915833, SRR915834, SRR915835) and non-irradiated (adults: SRR915836, SRR915837, SRR915838; pupae: SRR915839, SRR915840, SRR915844), Hawaiian population adults (SRR915845, SRR915846, SRR915848) and pupae (SRR915850, SRR915851, SRR915852), and C strain adults were checked and filtered using FastQC-0.72 and Trimmomatic-0.36.5 in Galaxy web-based platform (Andrews 2010; Bolger et al. 2014; Afgan et al. 2018) and mapped on C. capitata reference genome (Ccap_2.1; GCF_000347755.3 Papanicolaou et al. 2016; The i5k Initiative 2017) using HISAT2-2.1.0 (Kim et al. 2015). Sequence Alignment/Map files (SAM format) were filtered to keep only mapped reads and convert them to binary BAM sorted format using samtools-1.9 (Li et al. 2009).

Variant call format (VCF format) files were obtained and filtered using following commands of bcftools-1.9 (Li 2011), mpileup (generate VCF from BAM files), call (SNP/indel calling), merge (merge multiple VCF files from non-overlapping sample sets to create one multi-sample file) and filter (depth threshold $>10$ and mapped quality threshold $>20$ ). Two criteria at genotype level were applied: (1) homozygous alternative allele for all Vienna samples (irradiated and nonirradiated) and heterozygous or homozygous reference allele for all wild-type and C strain samples, and (2) heterozygous for all Vienna samples and a different genotype for all wildtype and $\mathrm{C}$ strain samples. One alternative criterion, without the previous filter according to depth and mapped quality, was applied to compare the regions where all Vienna samples did not show mapped reads, and all wild-type and C strain samples did, to detect putative indels.

In order to infer which mutations could be placed on the fifth chromosome of $C$. capitata, homologous to the $\mathrm{X}$ chromosome of Drosophila melanogaster (Kerremans and Franz 1994; Zacharopoulou et al. 2017), scaffolds of $C$. capitata (Ccap_2.1) were syntenic mapped against $D$. melanogaster (GCA_000001215.4 Release 6 plus ISO1 MT; The FlyBase Consortium/Berkeley Drosophila Genome Project/Celera Genomics 2014) using syMAP-4.2 (Soderlund et al. 2006, 2011). 


\section{C. capitata strains, wild populations and "C strain female $x$ Vienna strain male test cross"}

Irradiated and non-irradiated Vienna- $8^{\text {D53- }}$ strain (referred to as Vienna in the manuscript) individuals were obtained from the insect sterile production facility of Caudete de las Fuentes (Comunitat Valenciana, Spain). C strain originated from individuals was collected in non-treated experimental fields at Instituto Valenciano de Investigaciones Agrarias (IVIA; Valencia, Spain) in 2001 and is maintained in our laboratory without insecticide exposure (Magaña et al. 2007). Individuals from wild populations were collected in 2017 from areas in the Comunitat Valenciana (Spain) where a SIT program has been applied on a large-scale since 2007 (Wild-SIT codes 1-35), and between 2003 and 2012 from areas in Spain and Greece where large-scale SIT programs have never been implemented (Wild-noSIT, codes 36-44) (Table 1 and Fig. 1). Wild-SIT adults were obtained from medfly traps used at the Comunitat Valenciana for the monitoring of medfly populations in the areas where the SIT program is applied and delivered to our laboratory in ethanol at $70 \%$. In order to avoid potential contaminations by Vienna released males among the wild individuals collected in SIT areas, only Wild-SIT females were analyzed. A double revision of the sexing was performed attending to the sexual dimorphism of morphological characters in this species, first by the personnel in charge of the field sampling (Tragsa, Spain) and then by our own personnel after the reception of the material in the laboratory. Wild-noSIT adults were obtained by collecting fruits punctured by $C$. capitata and keeping them at the laboratory until the adults emerged (populations from La Rioja, Lleida and Zaragoza) or by medfly trap collection and delivery to our laboratory in ethanol at $70 \%$ (the rest of the Wild-noSIT populations).

To conduct the Vienna and $\mathrm{C}$ strains test cross, pupae of both Vienna and $\mathrm{C}$ strains were individualized in plastic boxes ( $4 \mathrm{~cm}$ diameter) to obtain recently emerged virgin $\mathrm{C}$ strain females and Vienna males. Emerged adults were collected daily, placed in ventilated plastic boxes $(18 \times 18.5 \times 18.5 \mathrm{~cm})$. Crosses consisted of 100 non-irradiated males of Vienna with 100 females from the $\mathrm{C}$ strains. Eggs were collected to obtain the F1 adults. Rearing followed the standard conditions previously described (Magaña et al. 2007).

\section{Genomic DNA extraction, PCR, Sanger sequencing and TaqMan genotyping assay}

Total DNA was extracted from heads and thorax of individuals using Speedtools tissue DNA extraction kit following manufacturer's instructions (Biotools, BIOTOOLS B\&M Labs, S.A., Madrid, Spain). PCRs to amplify candidate regions chosen after the in silico analyses and region with the marker selected by Sim et al. (2017) were performed as follows: $50-200 \mathrm{ng}$ of DNA, $0.4 \mu \mathrm{M}$ each primer, $1 \mathrm{U}$ AmpliTaq Gold, $1 \times$ PCR buffer II, $1.5 \mathrm{mM} \mathrm{MgCl}_{2}$ (Applied Biosystems) and $0.12 \mathrm{mM}$ dNTPs (Thermo Fisher Scientific). Cycling conditions consisted of an initial denaturation step at $95{ }^{\circ} \mathrm{C}$ for $10 \mathrm{~min}$, followed by 40 cycles of $95{ }^{\circ} \mathrm{C}$ for $30 \mathrm{~s}, 55-60{ }^{\circ} \mathrm{C}$ for $30 \mathrm{~s}$, and $72{ }^{\circ} \mathrm{C}$ for $30 \mathrm{~s}$ and a final step of $72{ }^{\circ} \mathrm{C}$ for $7 \mathrm{~min}$ to fully extend all PCR products. The following primers, designed by Primer3Plus software (Untergasser et al. 2007), were used for the amplification of each candidate regions (all sequences $5^{\prime}-3^{\prime}$ sense), V2 (F-V2, ATGGCCTTGTCAAAACCAAG and R-V2, AAT CGTGAGGTGCCAATACC) and V7 (F1-V7, CATATG TAGCCTTGGCTGGTG and/or F2-V7, GCCGCACGATAG TCAATGTATG in combination with R-V7, GTAGCGGAG TAGGTGAGCAGTTG). The region with the Sim's SNP marker (Sim et al. 2017) is defined in the present study as $\mathrm{V} 0$ and it was amplified with the following oligonucleotides (F-V0, ACATGGGTGGGAAAGGAAAT and R-V0, CTGTGCGGTGTTGAAGTGTT). The coordinates of amplified regions according to Ccap_2.1 reference genome are: V0 (NW_019378543.1: 1,259,953-1,260,067nt), V2 (NW_019378543.1: 1,616,020-1,616,291nt) and V7 (NW_019376417.1: 54,980-55,373nt).

Products were purified using QIAquick PCR purification kit (QIAGEN Group) and sequenced by Sanger at Secugen S.L. (Madrid, Spain) facilities. Depending on the sequence quality or the position of the polymorphism, one or both primers used in the PCR were used for sequencing. Since region $\mathrm{V} 7$ included an indel of $150 \mathrm{bp}$, heterozygous or homozygous individuals were detected using both F1-V7 and F2-V7 forward primers. Then, allele-specific conventional PCRs were performed for sequencing, using either the F1-V7 or the F2-V7 primer. Multiplex PCR was designed to simplify by agarose gel the detection of three possible genotypes, homozygous with deletion, homozygous without deletion and heterozygous.

TaqMan genotyping assay to detect the $\mathrm{V} 0$ marker ( $\mathrm{T}$ in Vienna strain (G/T Vienna male and T/T Vienna female genotypes) and $\mathrm{G} / \mathrm{G}$ wild genotype) was adapted from Sim et al. (2017) and performed at Secugen S.L facilities. A final volume of $5 \mu \mathrm{l}$ was used, including $2.5 \mu \mathrm{l}$ of TaqMan ${ }^{\mathrm{TM}}$ GTXpress $^{\mathrm{TM}}$ Master Mix, Custom TaqMan ${ }^{\mathrm{TM}}$ SNP Genotyping Assay, non-human 40x (36 $\mu \mathrm{M}$ each primer and $8 \mu \mathrm{M}$ the probe) (Thermo Fisher Scientific) and $2 \mu$ of DNA sample. Quantitative PCR protocol consisted of pre-read stage $\left(25^{\circ} \mathrm{C}, 30 \mathrm{~s}\right)$, hold stage $\left(95^{\circ} \mathrm{C}, 20 \mathrm{~s}\right), \mathrm{PCR}$ stage $\left(95^{\circ} \mathrm{C}, 3 \mathrm{~s}\right.$ and $\left.60{ }^{\circ} \mathrm{C}, 30 \mathrm{~s}\right)$ and post-read stage $\left(25^{\circ} \mathrm{C}, 30 \mathrm{~s}\right)$. Dataset was analyzed using QuantStudio ${ }^{\mathrm{TM}}$ Design and Analysis version 1.5.1 software (Applied Biosystems by Thermo Fisher Scientific). Each 96-well plate included three control individuals DNA of previously determined genotype by Sanger sequencing [one $\mathrm{C}$ strain individual (G/G genotype), one 
Table 1 Wild populations and strains used in the current study

\begin{tabular}{|c|c|c|c|}
\hline \multirow[t]{2}{*}{ Code } & \multirow[t]{2}{*}{ Location of collection/strain } & \multirow[t]{2}{*}{ Year } & $\begin{array}{l}\text { Number of } \\
\text { individuals }\end{array}$ \\
\hline & & & q \\
\hline
\end{tabular}

Wild populations

Wild-SIT-1

Wild-SIT-2

Almassora (Castelló, Spain)

Wild-SIT-3

Betxí (Castelló, Spain)

$2017 \quad 50 \quad-$

Wild-SIT-4

Onda (Castelló, Spain)

2017

Vila-real (Castelló, Spain)

Wild-SIT-5

Ador (València, Spain)

Wild-SIT-6

Alberic (València, Spain)

Wild-SIT-7

Villanueva de Castelló (València, Spain)

Wild-SIT-8

Wild-SIT-9

Wild-SIT-11

Sumacárcer (València, Spain)

Càrcer (València, Spain)

2017

2017

2017

2017

2017

2017

2017

Llocnou de Sant Jeroni (València, Spain)

2017

Alfauir (València, Spain)

2017

Wild-SIT-13

Ròtova (València, Spain)

Wild-SIT-14

Alzira (València, Spain)

Wild-SIT-15

Wild-SIT-16

Wild-SIT-17

Wild-SIT-18

Wild-SIT-19

Wild-SIT-20

Wild-SIT-21

Wild-SIT-22

Wild-SIT-23

Wild-SIT-24

Wild-SIT-25

Wild-SIT-26

Wild-SIT-29

Wild-SIT-30

Wild-SIT-31

Wild-SIT-32

Wild-SIT-33

Wild-SIT-34

Wild-SIT-35

Wild-noSIT-36

Wild-noSIT-38 ${ }^{a}$

Wild-noSIT-39

Wild-noSIT-40

Wild-noSIT-41

Wild-noSIT- $42^{\text {b }}$

Wild-noSIT-43

Wild-noSIT-44

Guadassuar (València, Spain)

Gandia (València, Spain)

Godelleta (València, Spain)

La Pobla de Farnals (València, Spain)

Monserrat (València, Spain)

Montroy (València, Spain)

Oliva (València, Spain)

Palma de Gandía (València, Spain)

Picassent (València, Spain)

Piles (València, Spain)

Puçol (València, Spain)

Puig (València, Spain)

Tavernes de la Valldigna (València, Spain)

2017

2017

2017

2017

2017

2017

2017

2017

2017

2017

2017

2017

2017

2017

2017

Xeraco (València, Spain)

Xeresa (València, Spain)

Torrent (València, Spain)

2017

2017

2017

Turís (València, Spain)

L’Atzubia (Alacant, Spain)

Pego (Alacant, Spain)

Jaraíz de la Vera (Cáceres, Spain)

Torre de Benagalbón (Málaga, Spain)

Cueva del Polvo (Tenerife, Spain)

Thessalonica (Greece)

Granadilla de Abona (Tenerife, Spain)

Albelda (La Rioja, Spain)

Menarguens (Lleida, Spain)

Villalengua (Zaragoza, Spain)

2017

2017

2017

2012

2003

2004

2004

2004

2004

2006

2006

Vienna- $8^{\mathrm{D} 53-}$
Vienna- $8^{\mathrm{D} 53-}$

Vienna- $8^{\text {D53- }}$

Control strain

V_NI (males non-irradiated)

$\mathrm{V}$ (females)

$\mathrm{C}^{\mathrm{b}}$

a(Beroiz et al. 2012)

b(Magaña et al. 2007)

Wild-SIT (codes 1-35) indicates individuals collected in 2017 from areas in the Comunitat Valenciana (Spain) where SIT program has been applied on a large-scale since 2007. Wild-noSIT (codes 36-44) indicates individuals collected between 2003 and 2012 from areas in Spain and Greece where SIT programs have never been implemented. Individuals from Vienna strain are indicated in the table as V_I (males irradiated), V_NI (males non-irradiated) and V (females). C refers to the C laboratory strain 
Wild populations (Wild-noSIT) collected in Spain and Greece between 2003-2012 Wild populations (Wild-SIT) collected in Comunitat Valenciana (Spain) in 2017

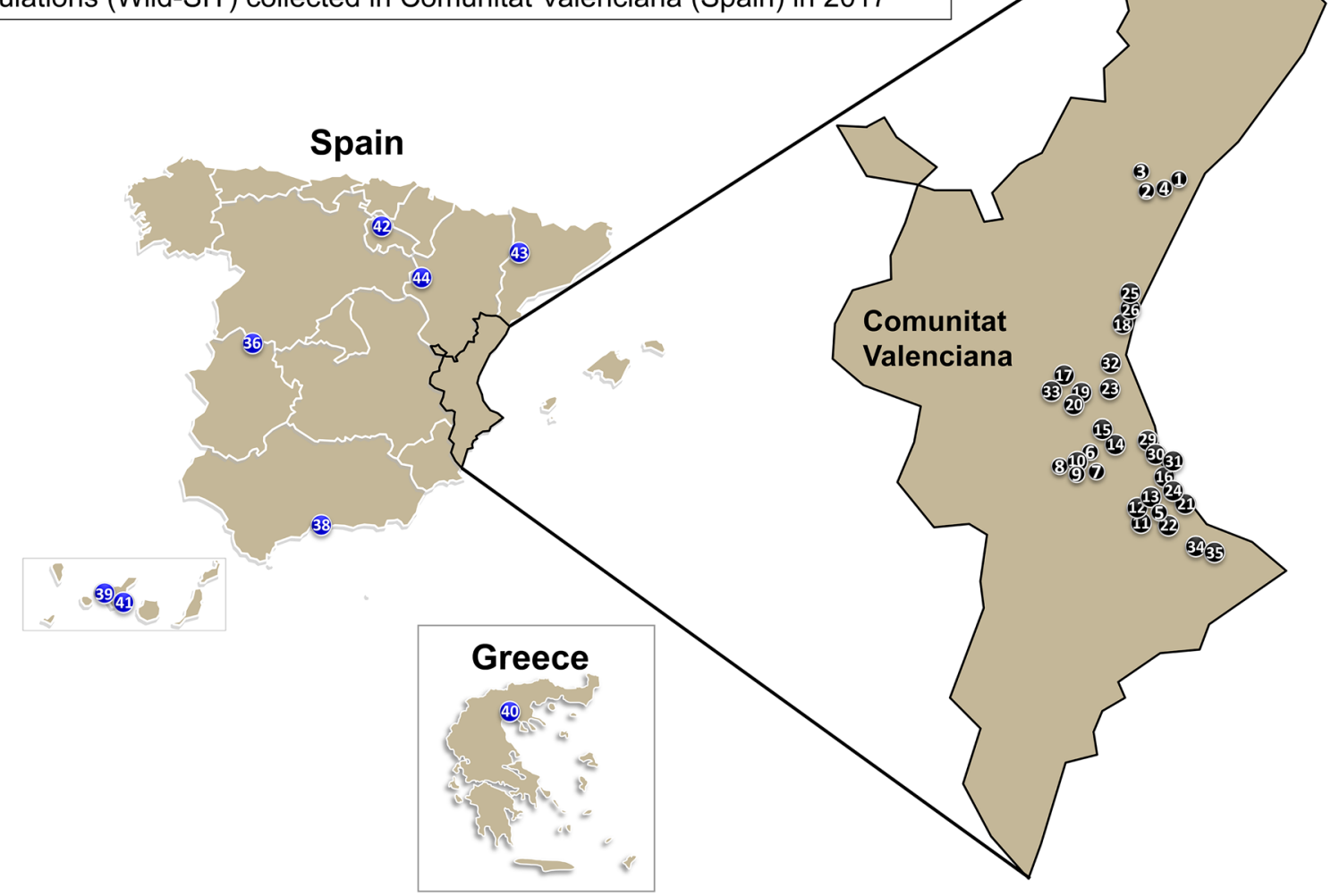

Fig. 1 Map of Spain and Greece showing the wild populations sampled. Black circles coded from 1 to 35 indicate Wild-SIT (wild populations collected in the Comunitat Valenciana (Spain) in 2017). Blue

Vienna male (G/T) and one Vienna female (T/T)] and one negative sample with miliQ water substituting the DNA template. After the analysis, all wild-type samples detected as $\mathrm{G} / \mathrm{T}$ or T/T genotypes (Vienna genotypes) were sequenced by Sanger to confirm the genotype determined by TaqMan. Furthermore, in order to confirm that these DNA samples did not come from field collected males misidentified as females, a chromosome Y-specific PCR was performed to detect males using primers CcYsp_F, CGAAGCCAGACA TACACGAGGAG and CcYsp_R, ACACTTACCGACATT GATTCCTG according to San Andrés et al. (2007). Finally, in order to detect specific markers from Vienna females, a mitochondrial Vienna marker was amplified and sequenced using primers Ccmt5495, AAATCACCACTTTGGATT TGAAGC and Ccmt5827, TGAAAATGGTAAACGTGA AGAGG designed by San Andrés et al. (2007).

The contigs assembly, alignment and visualization of the sequences were conducted using Geneious version 8.1.4 software (https://www.geneious.com).

The large datasets of sequence alignments and SNPs/ indels of the regions studied are available from the corresponding author on reasonable request. circles coded from 36 to 44 indicate Wild-noSIT (wild populations collected in Spain and Greece between 2003 and 2012)

\section{Results}

\section{Searching for genetic markers in the Vienna strain}

In silico analyses comparing RNA-Seq from Vienna strain to a wild Hawaiian population (Calla et al. 2014) and the C strain originated from Spanish populations allowed us to recover up to 313 positions that showed characteristic mutations in Vienna strain (108 SNPs/indels for the homozygous genotype of alternative alleles and $205 \mathrm{SNPs} /$ indels for the heterozygous genotype). In addition, the read mapping comparison analysis between Vienna and wild and $\mathrm{C}$ strain individuals showed regions with possible extensive indels characteristic of Vienna strain. Attending to the homology between the fifth chromosome of $C$. capitata and the X chromosome of D. melanogaster (Kerremans and Franz 1994; Zacharopoulou et al. 2017), those characteristic positions were further filtered by performing a syntenic analyses mapping $C$. capitata scaffolds to $D$. melanogaster chromosomes (Online Resource 1). A total of fifteen regions included in ten scaffolds (NW_019376291.1; NW_019376329.1; NW_019376401.1; NW_019376417.1; NW_019376419.1; 
NW_019376434.1; NW_019376569.1; NW_019378543.1; NW_019378574.1; NW_019378583.1) were amplified and sequenced from males and females (3-12 individuals) of the Vienna strain and compared to those of the $\mathrm{C}$ strain and Wild-noSIT populations. Two regions, V2 and V7, placed in two different scaffolds (NW_019378543.1 and NW_019376417.1, respectively) were chosen among the fifteen to be tested as Vienna molecular markers. Additionally, a Vienna marker identified by Sim et al. (2017), called in this paper V0 marker, was also included in the analysis. The summary of all different genotypes obtained for V0, V2 and V7 markers in Vienna, C strain and Wild-noSIT populations is shown in Table 2 (see Online Resource 2 for detailed information).

The V0 marker includes one SNP at coordinate 1,260,012nt (NW_019378543.1 scaffold). The following three genotypes were recovered through Sanger sequencing: heterozygous $\mathrm{G} / \mathrm{T}$ in all Vienna males $(n=4)$, homozygous T/T in all Vienna females $(n=3)$, homozygous $\mathrm{G} / \mathrm{G}$ in all $\mathrm{C}$ strain $(n=7)$ and Wild-noSIT individuals $(n=22)$. The V2 marker includes one SNP at coordinate 1,616,160nt (NW_019378543.1 scaffold). All Vienna males $(n=8)$ showed the heterozygous genotype G/A, and Vienna females $(n=4), \mathrm{C}$ strain $(n=11)$ and Wild-noSIT $(n=47)$ individuals showed the homozygous genotype $\mathrm{G} / \mathrm{G}$, except one female (Wild-noSIT-44_4 female) from Villalengua (Zaragoza, Spain), which showed the heterozygous genotype G/A. The V7 marker showed three interesting polymorphisms, including one indel of 150 base pairs (bp) between the coordinates 54,991 and 55,140nt, and two SNPs in the positions 55,204nt and 55,242nt (NW_019376417.1 scaffold). All Vienna individuals, males $(n=16)$ and females $(n=8)$, showed the
Table 2 Summary of genotypes found for V0, V2, and V7 markers obtained by Sanger sequencing from Vienna males (irradiated-V_I and non-irradiated-V_NI), Vienna females (V) and $\mathrm{C}$ strain males and females, $\mathrm{F} 1$ offspring $(\mathrm{C}$ females x Vienna males cross) and Wild-noSIT populations (codes 36-44)

\begin{tabular}{|c|c|c|c|c|c|}
\hline Codes & V0 & $\mathrm{V} 2$ & V7 & & \\
\hline V_I ठ & $\mathbf{G} / \mathbf{T}\left(4+5^{*}\right)$ & G/A (6) & A/A (deletion/deletion) G/G & $\mathrm{C} / \mathrm{C}$ & G/A (10) \\
\hline V_NI $\widehat{\jmath}$ & $\mathbf{G} / \mathbf{T}(5)^{*}$ & G/A (2) & A/A (deletion/deletion) $\mathrm{G} / \mathrm{G}$ & $\mathrm{C} / \mathrm{C}$ & G/A (6) \\
\hline $\mathrm{V}+$ & $\mathbf{T} / \mathbf{T}\left(3+4^{*}\right)$ & $\mathbf{G} / \mathbf{G}(4)$ & A/A (deletion/deletion) $\mathrm{G} / \mathrm{G}$ & $\mathrm{C} / \mathrm{C}$ & $\mathbf{A} / \mathbf{A}(8)$ \\
\hline $\mathrm{C} \mathrm{o}^{-1}$ & $\mathrm{G} / \mathrm{G}\left(3+3^{*}\right)$ & G/G (6) & A/A (insertion/insertion) $\mathrm{G} / \mathrm{G}$ & $\mathrm{T} / \mathrm{T}$ & G/G (5) \\
\hline $\mathrm{C} q$ & $\mathrm{G} / \mathrm{G}(4+3 *)$ & G/G (5) & A/A (insertion/insertion) $\mathrm{G} / \mathrm{G}$ & $\mathrm{T} / \mathrm{T}$ & $\mathrm{G} / \mathrm{G}(12)$ \\
\hline $\mathrm{F} 10$ & $\mathrm{G} / \mathbf{G}(7+2 *)$ & G/A (15) & $\mathrm{A} / \mathrm{A}$ (insertion/deletion) $\mathrm{G} / \mathrm{G}$ & $\mathrm{T} / \mathbf{C}$ & G/G (6) \\
\hline $\mathrm{F} 1$ ㅇ & $\mathrm{G} / \mathbf{T}(8+2 *)$ & G/G (20) & A/A (insertion/deletion) $\mathrm{G} / \mathrm{G}$ & $\mathrm{T} / \mathbf{C}$ & G/A (6) \\
\hline 36 ठ & $\mathrm{G} / \mathrm{G}\left(1+1^{*}\right)$ & G/G (2) & A/A (insertion/insertion) $\mathrm{G} / \mathrm{G}$ & $\mathrm{T} / \mathrm{T}$ & G/G (2) \\
\hline 36 ㅇ & $\mathrm{G} / \mathrm{G}(2+7 *)$ & G/G (4) & A/A (insertion/insertion) $\mathrm{G} / \mathrm{G}$ & $\mathrm{T} / \mathrm{T}$ & G/G (8) \\
\hline $38 \widehat{\jmath}$ & $\mathrm{G} / \mathrm{G}(1+1 *)$ & $\mathrm{G} / \mathrm{G}(2)$ & A/A (insertion/insertion) $\mathrm{G} / \mathrm{G}$ & $\mathrm{T} / \mathrm{T}$ & G/G (2) \\
\hline 38 ㅇ & $\begin{array}{l}\mathrm{G} / \mathrm{G}\left(6+3^{*}\right) \\
\mathrm{G} / \mathrm{T}(1)^{*}\end{array}$ & $\mathrm{G} / \mathrm{G}\left(6+1^{*}\right)$ & $\begin{array}{l}\text { A/A (insertion/deletion) } \mathrm{G} / \mathrm{G} \\
\mathrm{A} / \mathrm{A} \text { (insertion/insertion) } \mathrm{G} / \mathrm{G}\end{array}$ & $\begin{array}{l}\mathrm{T} / \mathbf{C} \\
\mathrm{T} / \mathrm{T}\end{array}$ & $\begin{array}{l}\text { G/A (6) } \\
\text { G/G (4) }\end{array}$ \\
\hline 39 ठ & $\mathrm{G} / \mathrm{G}(2)^{*}$ & G/G (2) & A/A (insertion/insertion) $\mathrm{G} / \mathrm{G}$ & $\mathrm{T} / \mathrm{T}$ & $\mathrm{G} / \mathrm{G}(2)$ \\
\hline 39 움 & $\mathrm{G} / \mathrm{G}(11)^{*}$ & G/G (4) & A/A (insertion/insertion) $\mathrm{G} / \mathrm{G}$ & $\mathrm{T} / \mathrm{T}$ & $\mathrm{G} / \mathrm{G}(11)$ \\
\hline $40 \mathrm{o}$ & G/G $(2)^{*}$ & G/G (2) & $\mathrm{A} / \mathrm{A}$ (insertion/deletion) $\mathrm{G} / \mathrm{G}$ & $\mathrm{T} / \mathbf{C}$ & G/A (2) \\
\hline 40 운 & $\mathrm{G} / \mathrm{G}\left(3+3^{*}\right)$ & G/G (4) & $\begin{array}{l}\text { A/A (insertion/insertion) } G / G \\
\text { A/A (insertion/deletion) } G / G\end{array}$ & $\begin{array}{l}\mathrm{T} / \mathrm{T} \\
\mathrm{T} / \mathrm{C}\end{array}$ & $\begin{array}{l}\text { G/G (3) } \\
\text { G/A (3) }\end{array}$ \\
\hline $41 \sigma^{\pi}$ & $\mathrm{G} / \mathrm{G}(2)^{*}$ & G/G (2) & $\begin{array}{l}\text { A/A (insertion/deletion) G/G } \\
\text { A/A (insertion/insertion) G/G }\end{array}$ & $\begin{array}{l}\mathrm{T} / \mathbf{C} \\
\mathrm{T} / \mathrm{T}\end{array}$ & $\begin{array}{l}\text { G/A (1) } \\
\text { G/G (1) }\end{array}$ \\
\hline 41 ㅇ & $\mathrm{G} / \mathrm{G}\left(2+5^{*}\right)$ & G/G (4) & $\begin{array}{l}\text { A/A (insertion/deletion) G/G } \\
\text { A/A (insertion/insertion) } G / G \\
\text { A/A (insertion/deletion) G/G }\end{array}$ & $\begin{array}{l}\mathrm{T} / \mathbf{C} \\
\mathrm{T} / \mathrm{T} \\
\mathrm{C} / \mathrm{C}\end{array}$ & $\begin{array}{l}\text { G/A (2) } \\
\text { G/G (3) } \\
\text { G/A (1) }\end{array}$ \\
\hline 42 우 & $\mathrm{G} / \mathrm{G}(2+2 *)$ & G/G (4) & A/A (insertion/insertion) $\mathrm{G} / \mathrm{G}$ & $\mathrm{T} / \mathrm{T}$ & G/G (4) \\
\hline $43 \hat{0}$ & $\mathrm{G} / \mathrm{G}(2)^{*}$ & G/G (2) & A/A (insertion/deletion) $\mathrm{G} / \mathrm{G}$ & $\mathrm{T} / \mathbf{C}$ & G/A (2) \\
\hline 43 q & $\mathrm{G} / \mathrm{G}(2+3 *)$ & G/G (4) & $\begin{array}{l}\text { A/A (insertion/deletion) G/G } \\
\text { A/A (insertion/deletion) G/G } \\
\text { A/A (insertion/insertion) G/G }\end{array}$ & $\begin{array}{l}\mathrm{T} / \mathrm{C} \\
\mathrm{T} / \mathrm{C} \\
\mathrm{T} / \mathrm{T}\end{array}$ & $\begin{array}{l}\text { G/A (1) } \\
\text { G/G (1) } \\
\text { G/G (6) }\end{array}$ \\
\hline 440 & $\mathrm{G} / \mathrm{G}(2)^{*}$ & G/G (2) & A/A (insertion/insertion) $\mathrm{G} / \mathrm{G}$ & $\mathrm{T} / \mathrm{T}$ & G/G (2) \\
\hline 44 ㅇ & $\mathrm{G} / \mathrm{G}\left(3+4^{*}\right)$ & $\begin{array}{l}\text { G/G (3) } \\
\text { G/A (1) }\end{array}$ & $\begin{array}{l}\text { A/A (insertion/insertion) G/G } \\
\text { A/A (insertion/deletion) G/G }\end{array}$ & $\begin{array}{l}\mathrm{T} / \mathrm{T} \\
\mathrm{T} / \mathrm{C}\end{array}$ & $\begin{array}{l}\text { G/G (6) } \\
\text { G/A (1) }\end{array}$ \\
\hline
\end{tabular}

Each line of each marker corresponds to one genotype (two allelic variants) found in one or more individual. Codes of indel: deletion/deletion (both alleles with 150- bp deletion), insertion/insertion (both alleles without 150- bp deletion) and insertion/deletion (one allele with 150- bp deletion). Numbers in parentheses indicate the number of individuals for each genotype. Bold nucleotides/indel note characteristic allele/s of Vienna -type. Asterisks indicate genotypes obtained by TaqMan assay or Sanger sequencing in the downstream analysis 
150-bp deletion in the two alleles, noted as deletion/deletion in Table 2 and Online Resource 2. No allele of $C$ strain individuals, males $(n=5)$ and females $(n=12)$, showed the deletion (insertion/insertion). The predominant genotype according to this polymorphic region in Wild-noSIT populations was the absence of deletion in both alleles $(n=54$; insertion/insertion), but there were also individuals with this deletion in one allele ( $n=20$; insertion/deletion). No WildnoSIT individual showed the deletion in both alleles. The SNP at position 55,204nt was always C/C in Vienna strain and $\mathrm{T} / \mathrm{T}$ or $\mathrm{T} / \mathrm{C}$ in $\mathrm{C}$ strain and Wild-noSIT populations. Remarkably, in all cases, the $\mathrm{C}$ at position $55,204 \mathrm{nt}$ was placed at the allele with the 150-bp deletion. This deletion was found in homozygosis in all individuals of the Vienna strain. Conversely, the $\mathrm{T}$ at position $55,204 \mathrm{nt}$ was placed at the allele without the deletion, with the only exception of the female Wild-noSIT-41_23 (see Online Resource 2). The third polymorphic position at coordinate 55,242nt was always G/A in Vienna males and A/A in Vienna females and homozygous $\mathrm{G} / \mathrm{G}$ or heterozygous $\mathrm{G} / \mathrm{A}$ in individuals from the Wild-noSIT populations. This SNP was also located at the allele with the deletion. All the Wild-noSIT individuals with the deletion showed the A polymorphism, except the female Wild-noSIT-43_2 (see Online Resource 2). The use of $\mathrm{V} 7$ indel, only detected in homozygosis in individuals of the Vienna strain, could simplify the identification of Vienna individuals, as it requires a single multiplex PCR for its detection (Online Resource 3). In addition, the sequencing of the second SNP $(55,242 \mathrm{nt})$ allows us to discriminate between Vienna males (G/A) and females (A/A).

\section{Vienna mutations in coding regions}

The SNP at the V2 marker is a silent substitution placed at the first coding exon of ATP-binding cassette subfamily $\mathrm{F}$ member 2 gene (XP_004530491.1). Orthologue genes are found in tephritids and in D. melanogaster Dmel_CG9281 (NP_001285284.1) (Online Resource 4). The gene is located on the X chromosome in D. melanogaster (http:// flybase.org). The polymorphisms at the V7 marker, the 150bp indel and two SNPs, are located at the first half, second exon, of the uncharacterized protein LOC101460932. Two isoforms are annotated on this locus XP_012159264.1 and XP_012159265.1, without and with the deletion, respectively. Notably, the deletion does not break the open reading frame (ORF) of the protein, but 50 residues are deleted in the mutated isoform, and no donor or acceptor splicing consensus is found at the genome explaining the mRNA isoform for XP_012159265.1. In addition, the mutation at 55,204nt is silent, but the SNP at 55,242nt causes a proline/serine substitution. The protein contains two ion channel domains (pfam07885) located at the second half of the protein. Putative orthologues for ion-channel protein XP_012159264.1 are found in the tephritids Bactrocera oleae, Bactrocera dorsalis, Bactrocera latifrons, Rhagoletis zephyria and Zeugodacus cucurbitae. Isoforms with the deletion are not found in the other tephritid species. A clear orthologue is not found in a BLASTp search against the D. melanogaster genome or in other species but tephritids. However, Dmel_CG42594, located on the $\mathrm{X}$ chromosome in D. melanogaster, is the most similar protein in this species $(45 \%$ coverage, E-value 1e-83) (Online Resource 5).

\section{Segregation of Vienna markers after crossing C and Vienna strains}

The segregation and chromosomal location of the V0, V2 and V7 genetic markers were analyzed in the offspring of the cross between $\mathrm{C}$ strain females and Vienna strain males (a schematic view is presented in Fig. 2). Results are summarized in Table 2 (detailed results at the individual level are shown in Online Resource 6). Assuming that aneuploid individuals are not viable, the characteristic Vienna mutations exclusively inherited by F1 females should be located on the non-translocated chromosome five. Conversely, those exclusively inherited by F1 males should be on one of the two fragments-either $Y-5$ or $5-Y-$ of the $T(Y ; 5)$ translocation. Interestingly, the three Vienna markers (V0, V2 and V7) segregated differentially in males and females of the F1 offspring, which suggests their sex linkage. The Vienna markers V0 and V2 are located at the same scaffold NW_019378543.1 (T at 1,260,012nt and A at 1,616,160nt positions, respectively, characterizing Vienna males); however, they behaved differently. The V0 marker segregated according to the location of the SNP " $T$ " on the non-translocated fifth chromosome, since only F1 females inherited the characteristic Vienna SNP " $T$ " (all females were genotyped as $\mathrm{G} / \mathrm{T}$ and all males as $\mathrm{G} / \mathrm{G}$ ). On the contrary, V2 segregated accordingly to the location of the SNP " $A$ " on the translocated $Y-5$ or 5- $Y$ chromosomes, since only $F 1$ males inherited the characteristic Vienna SNP " $A$ " (all males and all females genotyped as G/A and G/G, respectively). The V7 marker (one indel and two SNPs at scaffold NW_019376417.1) also segregated differently in males and females. The second SNP " $A$ " at 55,242nt, only found in Vienna males in heterozygosis (G/A), was only inherited by F1 females. Thus, this polymorphism could only be located on the non-translocated fifth chromosome.

\section{Searching for Vienna markers into wild individuals}

With the aim of extensively searching for Vienna markers in wild individuals, we analyzed a total of 1060 DNA samples to detect the V0 marker using the TaqMan reaction described by Sim et al. (2017). These samples included: (1) 884 females collected in 2017 from locations at the 


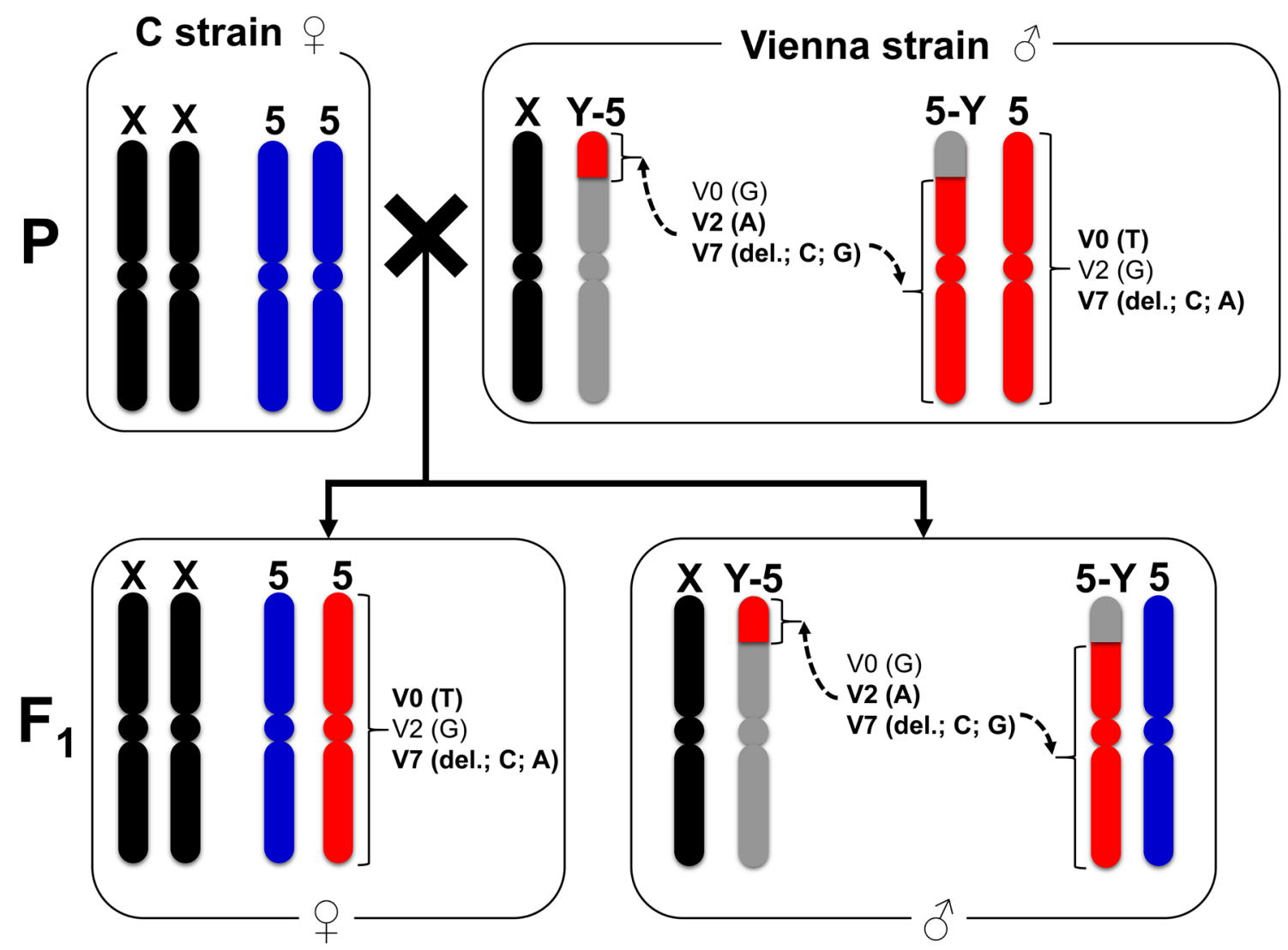

Fig. 2 Chromosomal scheme for the cross between $\mathrm{C}$ strain females and Vienna non-irradiated males, and its F1 progeny. Hypotheses for location of the genetic markers (V0, V2 and V7) on the fifth chromosome according to parental and offspring genotypes obtained by amplification and Sanger sequencing. The specific Vienna allelic variant for each marker appears in parentheses. Colors indicate $\mathrm{X}$ chro-

Comunitat Valenciana where the SIT program is applied (Wild-SIT populations); (2) 126 females collected between 2003 and 2012 in areas were no large-scale SIT program has been implemented (Wild-noSIT populations); (3) 9 males and 10 females of the F1 offspring after crossing Vienna males with $\mathrm{C}$ strain females; (4) 9 Vienna irradiated and 5 non-irradiated males; (5) 7 Vienna females; and (6) 3 males and 7 females of the $\mathrm{C}$ strain. The TaqMan reaction allowed the identification of G/G, G/T or T/T genotypes for 1,260,012nt at scaffold NW_019378543.1, being the allele with $\mathrm{T}$ a marker for the Vienna strain (Online Resources 7 and 8). Only 16 samples showed undetermined genotypes. Additionally, all wild-type individuals which showed the Vienna genotype in the TaqMan assay were confirmed by Sanger (Table 3).

As expected and according to previous results, all Vienna males $(n=14)$ showed the $\mathrm{G} / \mathrm{T}$ genotype, and all Vienna females $(n=7)$ showed the T/T genotypes. In addition, all $\mathrm{C}$ strain females $(n=7)$ and males $(n=3)$ showed the G/G genotype. Also, F1 males and females showed mosome (black), Y chromosome (gray), the fifth chromosome of C (blue) and Vienna (red) strains. "del." means deletion. Dashed arrows indicate the two possible locations of the markers in the two elements of the $T(Y ; 5)$ translocation. Bold nucleotides indicate the characteristic Vienna polymorphisms

as expected $\mathrm{G} / \mathrm{G}(n=9)$ and $\mathrm{G} / \mathrm{T}(n=10)$, respectively. Among the Wild-noSIT females collected at areas where no SIT program is applied, all $(n=119)$ showed the $\mathrm{G} / \mathrm{G}$ genotype, except one female collected at Torre de Benagalbón in 2003 (code 38_24) that showed the Vienna characteristic genotype G/T. Remarkably, the analysis of WildSIT females collected at areas where the SIT program is applied revealed that $2.2 \%$ (from 875 of known genotype) contained the V0 marker (18 showing the G/T Vienna male genotype and 1 showing the T/T Vienna female genotype). These individuals with V0 Vienna genotype were found in 15 of the 32 Wild-SIT populations analyzed. In addition, two of these populations (Almassora and Gandía) showed the G/T genotype in up to 3 individuals from the 50 analyzed. In order to discard the presence of recaptured Vienna males among these field individuals, their female sex was confirmed by the impossibility of amplifying Y-specific sequences using the oligonucleotides designed by San Andrés et al. (2007). Results are shown in Online Resource 9. 
Table 3 Genotypes obtained by direct sequencing of V0, V2, and V7 markers from individuals showing a Sim's SNP Vienna genotype after TaqMan analysis

\begin{tabular}{|c|c|c|c|c|c|}
\hline Codes & V0 & V2 & V7 & & \\
\hline 1_14 ㅇ & $\mathrm{G} / \mathbf{T}$ & G/A & $\begin{array}{l}\text { A/A (deletion/deletion) } \\
\text { G/G }\end{array}$ & $\mathrm{C} / \mathrm{C}$ & G/A \\
\hline $1 \_30$ ㅇ & $\mathrm{G} / \mathbf{T}$ & G/A & $\begin{array}{l}\text { A/A (deletion/deletion) } \\
\text { G/G }\end{array}$ & $\mathrm{C} / \mathrm{C}$ & G/A \\
\hline 1_43 우 & $\mathrm{G} / \mathbf{T}$ & $\mathrm{G} / \mathrm{G}$ & $\begin{array}{l}\text { A/A (insertion/insertion) } \\
\text { G/G }\end{array}$ & $\mathrm{T} / \mathrm{T}$ & $\mathrm{G} / \mathrm{G}$ \\
\hline 3_33 우 & $\mathrm{G} / \mathbf{T}$ & $\mathrm{G} / \mathrm{G}$ & $\begin{array}{l}\text { A/A (insertion/deletion) } \\
\text { G/G }\end{array}$ & $\mathrm{T} / \mathbf{C}$ & G/A \\
\hline 4_1 우 & $\mathrm{G} / \mathbf{T}$ & G/A & $\begin{array}{l}\text { A/A (insertion/deletion) } \\
\text { G/G }\end{array}$ & $\mathrm{T} / \mathbf{C}$ & G/G \\
\hline 5_16우 & $\mathrm{G} / \mathbf{T}$ & $\mathrm{G} / \mathrm{G}$ & $\begin{array}{l}\text { A/A (insertion/insertion) } \\
\text { G/G }\end{array}$ & $\mathrm{T} / \mathrm{T}$ & G/G \\
\hline 13_2 9 & $\mathrm{~T} / \mathbf{T}^{\#}$ & $\mathrm{G} / \mathrm{G}$ & $\begin{array}{l}\text { A/A (insertion/deletion) } \\
\text { G/G }\end{array}$ & $\mathrm{T} / \mathbf{C}$ & G/A \\
\hline 16_9 ㅇ & G/T & $\mathrm{G} / \mathrm{G}$ & $\begin{array}{l}\text { A/A (insertion/insertion) } \\
\text { G/G }\end{array}$ & $\mathrm{T} / \mathrm{T}$ & G/G \\
\hline 16_18우 & $\mathrm{G} / \mathbf{T}$ & $\mathrm{G} / \mathrm{G}$ & $\begin{array}{l}\text { A/A (insertion/insertion) } \\
\text { G/G }\end{array}$ & $\mathrm{T} / \mathrm{T}$ & G/G \\
\hline 16_32우 & $\mathrm{G} / \mathbf{T}$ & $\mathrm{G} / \mathrm{G}$ & $\begin{array}{l}\text { A/A (insertion/insertion) } \\
\text { G/G }\end{array}$ & $\mathrm{T} / \mathrm{T}$ & G/G \\
\hline 17_40우 & $\mathrm{G} / \mathbf{T}$ & $\mathrm{G} / \mathrm{G}$ & $\begin{array}{l}\text { A/A (insertion/insertion) } \\
\text { G/G }\end{array}$ & $\mathrm{T} / \mathrm{T}$ & G/G \\
\hline 18_23우 & $\mathrm{G} / \mathbf{T}$ & $\mathrm{G} / \mathrm{G}$ & $\begin{array}{l}\text { A/A (insertion/deletion) } \\
\text { G/G }\end{array}$ & $\mathrm{T} / \mathbf{C}$ & G/A \\
\hline 20_21우 & $\mathrm{G} / \mathbf{T}$ & $\mathrm{G} / \mathrm{G}$ & $\begin{array}{l}\text { A/A (insertion/deletion) } \\
\text { G/G }\end{array}$ & $\mathrm{T} / \mathbf{C}$ & G/A \\
\hline 22_15 우 & $\mathrm{G} / \mathbf{T}$ & $\mathrm{G} / \mathrm{G}$ & $\begin{array}{l}\text { A/A (insertion/deletion) } \\
\text { G/G }\end{array}$ & $\mathrm{T} / \mathbf{C}$ & G/A \\
\hline 23_47우 & $\mathrm{G} / \mathbf{T}$ & $\mathrm{G} / \mathrm{G}$ & $\begin{array}{l}\text { A/A (insertion/deletion) } \\
\text { G/G }\end{array}$ & $\mathrm{C} / \mathbf{C}$ & G/A \\
\hline 24_39 9 & $\mathrm{G} / \mathbf{T}$ & $\mathrm{G} / \mathrm{G}$ & $\begin{array}{l}\text { A/A (insertion/deletion) } \\
\text { G/G }\end{array}$ & $\mathrm{T} / \mathbf{C}$ & G/A \\
\hline 29_7 ㅇ & $\mathrm{G} / \mathbf{T}$ & $\mathrm{G} / \mathrm{G}$ & $\begin{array}{l}\text { A/A (insertion/deletion) } \\
\text { G/G }\end{array}$ & $\mathrm{T} / \mathbf{C}$ & G/A \\
\hline 32_7 우 & $\mathrm{G} / \mathbf{T}$ & $\mathrm{G} / \mathrm{G}$ & $\begin{array}{l}\text { A/A (insertion/deletion) } \\
\text { G/G }\end{array}$ & $\mathrm{T} / \mathbf{C}$ & $\mathrm{G} / \mathbf{G}$ \\
\hline 33_29우 & $\mathrm{G} / \mathbf{T}$ & $\mathrm{G} / \mathrm{G}$ & $\begin{array}{l}\text { A/A (insertion/deletion) } \\
\text { G/G }\end{array}$ & $\mathrm{T} / \mathbf{C}$ & G/A \\
\hline 38_24 우 & $\mathrm{G} / \mathbf{T}$ & G/G & $\begin{array}{l}\text { A/A (insertion/deletion) } \\
\text { G/G }\end{array}$ & $\mathrm{T} / \mathbf{C}$ & G/A \\
\hline
\end{tabular}

All individuals are females and belong to Wild-SIT populations (codes 1-33) from Spain collected in 2017, excepting one WildnoSIT (code 38). Genotypes note both alleles (allele 1/allele 2) for each locus. Codes of indel: deletion/deletion (both alleles with 150bp deletion), insertion/insertion (both alleles without 150- bp deletion) and insertion/deletion (one allele with 150- bp deletion). Bold nucleotides/indel note characteristic allele/s Vienna -type. Both V7 alleles were amplified and sequenced separately. Hash notes the V0 Vienna female-type genotype detected

To further study the presence of Vienna molecular markers in wild Spanish populations, the sequence of regions V2 and V7 was also obtained by Sanger in wild females putatively related to Vienna strain individuals according to the marker from V0 region. Results are shown in Table 3. Notably, two females, Wild-SIT-1_14 and Wild-SIT-1_30, from Almassora showed the three markers (V0, V2 and V7) corresponding to the Vienna male genotype, including the homozygous 150-bp deletion in both alleles of V7 marker. The V7 Vienna marker was found in 12 of the 20 individuals in which the V0 Vienna marker was detected. The presence of the mitochondrial Vienna marker (San Andrés et al. 2007) in all individuals with G/T Vienna genotype of V0 marker was analyzed. Interestingly, two individuals, WildSIT-1_14 and Wild-SIT-1_30, showed the mitochondrial Vienna marker (Online Resource 10).

\section{Discussion}

The SIT is considered to be one of the most environmentally friendly insect pest control methods (IAEA 2020). Species specificity and its successful adoption in IPM strategies are among the advantages. Both classical and transgenic GSS have been developed, but SIT does not involve the use of transgenic processes in the case of medfly, since the released males belong to the laboratory selected Vienna strain that are sterilized by irradiation. The efficacy and reduced environmental impact of the method are based on the idea that sterile insects are not self-replicating and therefore cannot become established in the environment. However, 100\% sterilization by radiation is not achieved in medfly (RamírezSantos et al. 2017), since a compromise exists between the intensity of radiation and the competitiveness of irradiated males (Sayed 2013). In this paper, making use of previous nuclear (Sim et al. 2017) and mitochondrial (Gasparich et al. 1995; Spanos et al. 2000; San Andrés et al. 2007) Vienna molecular markers, together with two novel nuclear markers, we report the detection of Vienna genetic markers in wild individuals.

The two novel nuclear markers (V2 and V7) have been selected after RNA-Seq in silico analysis, amplification and Sanger sequencing. They complement the available nuclear (V0) Vienna marker in our strategy to identify introgressed individuals, since our results have shown that the V0 marker was present in one Wild-noSIT individual. The genotypes of the V2 and V7 markers did not show variability in Vienna males, females and the F1 offspring, which highlight their potential to discriminate between Vienna and wild individuals. However, we have found that they can also occur at a low frequency in natural Wild-noSIT populations. Thus, V2 showed the Vienna male genotype (G/A) in all Vienna males and only in one Wild-noSIT female. The V7 deletion was only found in both alleles in Vienna flies comparing to 
Wild-noSIT populations. In addition, focusing on Vienna flies, both V2 and V7 markers showed a sex-linking SNP since V2 G/T genotype was only detected in Vienna males and G/G in Vienna females. Similarly, the G/A genotype of the second SNP in the V7 markers was only detected in Vienna males and the A/A genotype in Vienna females. Remarkably, only one Wild-noSIT individual showed two Vienna markers, whereas 13 of the 19 Wild-SIT individuals carrying the V0 marker showed at least one of the two novel nuclear markers and two individuals showed all Vienna markers, including the mitochondrial marker.

Both novel markers (V2 and V7) are localized at gene coding sequences. This contrasts with the Vienna nuclear marker V0 previously identified by Sim et al. (2017), which is located at an intergenic region. Both proteins have orthologue counterparts in other tephritids and show high similarity with $D$. melanogaster genes located on the $\mathrm{X}$ chromosome, which shows homology to the fifth chromosome in C. capitata (Kerremans and Franz 1994; Zacharopoulou et al. 2017). The characteristic SNP of the V2 Vienna marker represents a silent substitution at the coding sequence of the ATP-binding cassette subfamily F member 2 gene, and it is not expected to influence the protein function. However, the gene located at the $\mathrm{V} 7$ region in the Vienna strain contains a deletion of 50 residues and a proline/serine substitution. The ion channel protein coded by this gene at the $\mathrm{V} 7$ region may be involved in many aspects of biology including melanogenesis and pigmentation (Bellono et al. 2014) or temperature sensitivity (Kunkel et al. 2000). However, with the data available at present, it is premature to speculate about the impact of these mutations on the functionality of the protein or about the relationship between the V7 marker with any of two mutations ( $t s l$ and $w p$ ) characterizing Vienna GSS. However, it is worth noting that a similar deletion at this gene is not found in other tephritids having highly similar orthologues. This would suggest a recent event causing the deletion, which could have originated after the speciation of $C$. capitata.

A precise chromosomal location for the markers selected in this study cannot be given with the available data. However, their location on translocated $Y-5$ or $5-Y$ chromosomes (V2) and non-translocated chromosome 5 (V0 and V7) is demonstrated by the sex-linked inheritance in the F1 progeny obtained by crossing Vienna males with $\mathrm{C}$ strain females (see Fig. 2). The V0 marker, found at the same scaffold that the V2 marker, was reported to be in near-perfect linkage disequilibrium with the pupal color phenotype (Sim et al. 2017). However, the Vienna SNP "T" of V0 marker is only detected in F1 females as opposed to the Vienna SNP "A" of $\mathrm{V} 2$ marker only detected in F1 males. This suggests that the V0 marker is located on the non-translocated chromosome 5 and the Vienna V2 SNP on the translocated $Y-5$ or 5-Y chromosomes. The second SNP "A" of V7 marker shows the same segregation of the V0 marker, which is only detected in F1 females, suggesting its location on the non-translocated chromosome 5 (Table 2; Online Resource 6).

We have identified the V0 marker on 19 wild medfly females captured at the area where SIT is applied (WildSIT), 18 showing the Vienna male genotype and 1 showing the Vienna female genotype, which accounts for $2.2 \%$ of the females collected in 2017 at the SIT area in the Comunitat Valenciana. The presence of V0 in wild populations represents evidence of the introgression of Vienna into natural populations, since the nuclear V0 marker has been reported to be efficient and consistent in the discrimination between Vienna strain and wild-type adults from wild individuals collected in different countries (Sim et al. 2017). Notably, Sim et al. (2017) observed that several wild individuals collected in the Comunitat Valenciana showed the Vienna genotype. The authors concluded that these individuals most probably corresponded to recapture of Vienna males, since they did not track the sex of the medflies collected in their study. However, in light of our results, those individuals could well correspond to wild descendants from Vienna males, and therefore, we cannot rule out either option, recapture of GSS males or introgressed individuals. The analysis of the two novel markers V2 and V7, on the wild-SIT females with genotype for the V0 marker, further supported the Vienna introgression, since three females $\left(1 \_14 ; 1 \_30 ; 4 \_1\right.$; Table 3 ) from those 19 were positive for both markers, and up to 13 of those showed the deletion in the V7 region.

Interestingly, a Vienna mitochondrial marker (Gasparich et al. 1995; Spanos et al. 2000; San Andrés et al. 2007) was also found in two individuals (1_14 and 1_30). As the mitochondrial genome is inherited from the maternal progenitor, it is plausible that a Vienna female could have been involved in the crossings that gave rise to these individuals. However, the possibility of releasing irradiated non-sterilized females is highly unlikely, and the presence of the mitochondrial marker in wild individuals can also be explained by natural occurrence or by the accidental release of non-irradiated females. The rest of introgressed individuals can be descendants of Vienna males, according to the absence of the mitochondrial marker. Interestingly, this last group included the individual (13_2) that showed the Vienna female homozygous genotype (T/T) for the V0 marker, but did not show the Vienna mitochondrial marker. Thus, we discard the possibility that this individual is a descendant of male and female Vienna individuals. Instead, it could be the result of a cross between two introgressed wild individuals or one introgressed female and a Vienna male.

We have found that the three Vienna markers can occur at a low frequency in natural populations from areas where large-scale SIT programs have never been implemented. Among all the individuals analyzed from Wild-noSIT populations, one collected in Málaga (Spain) in 2003 (38_24) 
showed the V0 Vienna marker, one collected at Zaragoza (Spain) in 2006 (44_4) showed the V2 Vienna marker and nineteen individuals from other wild-noSIT populations showed the V7 marker deletion in heterozygosis. The presence of these markers in Spanish wild-noSIT populations may be explained by the release of Vienna individuals performed in a pilot program initiated in the Comunitat Valenciana in 2003, which consisted of weekly releases of between 10 and 20 million sterile males with an annual total of 1500 million (Primo-Millo et al. 2003), and their transfer to the Wild-noSIT areas tested. However, alternative explanations as the natural presence of these Vienna markers at low frequency in wild populations in the studied areas cannot be fully discarded. The V7 marker was also found in five individuals from Greece where a medfly SIT program is not implemented. These results may be compatible with the natural presence of this allele in natural populations, since as far as we know the only field experiment reported in Greece refers to the release of 250,000 tsl sterile males from the Vienna-42 $(T(Y ; 5) 1-61)$ strain in citrus orchards at the island of Chios in September 1992 (Hendrichs et al. 1993), geographically separated from Thessalonica, where medflies analyzed in this study were collected.

In spite of the presence of Vienna markers at a low frequency in Wild-noSIT populations, the analysis of one mitochondrial and three nuclear markers, V0 (Sim et al. 2017), $\mathrm{V} 2$ and V7, in single individuals offers a strong evidence for the presence of descendants from Vienna males and females in Spanish Wild-SIT populations. The Sim's marker (V0) was detected in 19 individuals from Wild-SIT natural populations $(2.2 \%)$ and only one individual $(0.5 \%)$ from WildnoSIT natural populations. In addition, 13 individuals of the 19 Wild-SIT showed at least one Vienna allele of V7 region, which includes the deletion and two characteristic SNPs of Vienna, and two individuals showed all Vienna markers, including the mitochondrial marker. Vienna markers may have been introduced in field populations by (1) the release of irradiated but non-fully sterile Vienna males or females skipping the sex selection and (2) the unintended escape of non-irradiated flies. Nevertheless, the presence of Vienna markers in the Wild-SIT populations analyzed for reasons other than the introgression from Vienna individuals cannot be fully discarded, which points out the utility of combining several of the available Vienna markers and the necessity to continue investigating for more specific ones. The low percentage of non-fully sterility among Vienna males and their lower competitiveness (Calkins and Parker 2005; Robinson 2005; Calla et al. 2014; Ramírez-Santos et al. 2017) may be compensated by their mass release, and descendants from irradiated males may have survived in the field. In addition, irradiated non-fully sterile males might be introducing random mutations in wild populations. Notably, gamma radiation induces mutagenesis (Tonzetich et al. 1988) and a transcriptomic analysis comparing GSS irradiated versus non-irradiated medflies pointed to the randomness of the irradiation effects on the genome (Calla et al. 2014). The risk of introducing non-fully sterile GSS irradiated individuals into natural populations may be difficult to predict or assess. Nevertheless, it should be minimized and taken into account in the application of the SIT technology to avoid the undesired release of non-fully sterile GSS individuals into the field.

\section{Author contributions}

PHC and FO conceived the study. PHC, FO, RS, AGA, ELE and LS participated in the design of the experiments and the interpretation of the results. RS, AGA and ELE performed the experiments. RS and PHC wrote the first draft of the manuscript. All authors read, corrected and approved the manuscript.

Supplementary Information The online version of this article (https:// doi.org/10.1007/s10340-021-01337-8).

Acknowledgements This work received financial support from the Spanish MINECO (AGL2016-76516-R). We gratefully acknowledge Ignacio Pla and Jaime García de Oteyza (Tragsa Group) for providing Wild-SIT and Vienna individuals; Pedro Ros (INIA), Jesús Olivero Anarte (U. Málaga), Emilio García (Consejería de Agricultura, Andalucía), Nikos Papadopoulos (U. Thessaly), Aurelio Carnero (ICIA), Estrella Hernández (ICIA), Vicente Marco (U. Rioja), Xavier Miarnau (IRTA) and Vicente Marco (U. Rioja) for providing Wild-noSIT individuals; and Secugen S.L for conducting Sanger sequencing and TaqMan assay.

Funding This study was funded by the Spanish MINECO (AGL2016-76516-R).

Data availability All curated datasets are available in Online Resources. The large datasets are available from the corresponding author on reasonable request. RNA-Seq reads of $\mathrm{C}$ strain medflies mapped on the Ceratitis capitata reference genome (Ccap_2.1) are available in the European Nucleotide Archive (ENA) (accessions: ERR4690325, ERR4690326 and ERR4690327).

\section{Compliance with ethical standards}

Conflict of interest The authors declare that there is no conflict of interest/competing interests.

Open Access This article is licensed under a Creative Commons Attribution 4.0 International License, which permits use, sharing, adaptation, distribution and reproduction in any medium or format, as long as you give appropriate credit to the original author(s) and the source, provide a link to the Creative Commons licence, and indicate if changes were made. The images or other third party material in this article are included in the article's Creative Commons licence, unless indicated otherwise in a credit line to the material. If material is not included in the article's Creative Commons licence and your intended use is not permitted by statutory regulation or exceeds the permitted use, you will 
need to obtain permission directly from the copyright holder. To view a copy of this licence, visit http://creativecommons.org/licenses/by/4.0/.

\section{References}

Afgan E, Baker D, Batut B et al (2018) The Galaxy platform for accessible, reproducible and collaborative biomedical analyses: 2018 update. Nucleic Acids Res 46:537-544

Andrews S (2010) FastQC: a quality control tool for high throughput sequence data. Available online at: http://www.bioinformatics.bab

Argilés R, Tejedo-Tormo V (2007) La lucha contra la mosca de la fruta mediante la técnica del insecto estéril en la Comunitat Valenciana. Levante Agrícola: Revista internacional de cítricos 385:157-162

Arouri R, Le Goff G, Hemden H et al (2015) Resistance to lambdacyhalothrin in Spanish field populations of Ceratitis capitata and metabolic resistance mediated by $\mathrm{P} 450$ in a resistant strain. Pest Manag Sci 71:1281-1291

Bakri A, Mehta K, Lance DR (2005) Sterilizing insects with ionizing radiation. In: Dyck VA, Hendrichs J, Robinson AS (eds) Sterile insect technique. Principles and practice in area-wide integrated pest management. Springer, Dordrecht, The Netherlands, pp 233-268

Barr NB (2009) Pathway analysis of Ceratitis capitata (Diptera: Tephritidae) using mitochondrial DNA. J Econ Entomol 102:401-411

Bellono NW, Escobar IE, Lefkovith AJ et al (2014) An intracellular anion channel critical for pigmentation. Elife 3:e04543

Beroiz B, Ortego F, Callejas C et al (2012) Genetic structure of Spanish populations of Ceratitis capitata revealed by RAPD and ISSR markers: implications for resistance management. Span J Agric Res 10:815-825

Bolger AM, Lohse M, Usadel B (2014) Trimmomatic: a flexible trimmer for Illumina sequence data. Bioinformatics 30:2114-2120

Busch-Petersen E (1990) Temperature sensitive lethal factors and puparial colour sex separation mechanisms in the Mediterranean fruit fly, Ceratitis capitata (Wied). Joint FAO/IAEA Div. of Nuclear Techniques in Food and Agriculture, Vienna (Austria); Panel proceedings series; pp 115-127; IAEA; Vienna (Austria); Final research co-ordination meeting on development of genetic sexing mechanisms in fruit flies through manipulation of radiation induced conditional lethals and other genetic measures; Colymbari, Crete (Greece); 3-7 Sep 1988

Caceres C (2002) Mass rearing of temperature sensitive genetic sexing strains in the Mediterranean fruit fly (Ceratitis capitata). Genetica 116:107-116

Caceres C, Cayol JP, Enkerlin W, et al (2004) Comparison of Mediterranean fruit fly (Ceratitis capitata) (Tephritidae) bisexual and genetic sexing strains: development, evaluation and economics. In: proceeding of 6th international fruit fly symposium. Stellenbosch, South Africa, pp 367-381

Calkins CO, Parker AG (2005) Sterile insect quality. In: Dyck VA, Hendrichs J, Robinson AS (eds) Sterile insect technique. Principles and practice in area-wide integrated pest management. Springer, Dordrecht, The Netherlands, pp 269-296

Calla B, Hall B, Hou S, Geib SM (2014) A genomic perspective to assessing quality of mass-reared SIT flies used in Mediterranean fruit fly (Ceratitis capitata) eradication in California. BMC Genom 15:1-19

Enkerlin WR (2005) Impact of fruit fly control programmes using the sterile insect technique. In: Dyck VA, Hendrichs J, Robinson AS (eds) Sterile insect technique. Principles and practice in area-wide integrated pest management. Springer, Dordrecht, The Netherlands, pp 651-676
EPPO (2020) European and Mediterranean Plant Protection Organization. Ceratitis capitata (CERTCA). https://gd.eppo.int/taxon/ CERTCA (Accessed on june 2020)

Fisher K (2000) Genetic sexing strains of Mediterranean fruit fly (Diptera: Tephritidae): quality in mass-reared temperature-sensitive lethal strains treated at high temperatures. Hortic Entomol 93:394-402

Franz G (2002) Recombination between homologous autosomes in medfly (Ceratitis capitata) males: type- 1 recombination and the implications for the stability of genetic sexing strains. Genetica 116:73-84

Franz G (2005) Genetic sexing strains in Mediterranean fruit fly, an example for other species amenable to large-scale rearing for the sterile insect technique. In: Dyck VA, Hendrichs J, Robinson AS (eds) Sterile insect technique. Principles and practice in area-wide integrated pest management. Springer, Dordrecht, The Netherlands, pp 427-452

Gasparich GE, Sheppard WS, Han H-Y et al (1995) Analysis of mitochondrial DNA and development of PCR-based diagnostic molecular markers for Mediterranean fruit fly Ceratitis capitata populations. Insect Mol Biol 4:61-67

Generalitat Valenciana (2016) Campaña oficial de lucha contra Ceratitis capitata en la Comunitat Valenciana 2016. http://www.agroa mbient.gva.es/documents/163214705/163420753/Campa\%25F1a +Lucha+Ceratitis+capitata+2016.pdf/4e185315-185d-4df39906-9167327ffb34

Guillem-Amat A, Sánchez L, López-Errasquín E et al (2020) Field detection and predicted evolution of spinosad resistance in Ceratitis capitata. Pest Manag Sci. https://doi.org/10.1002/ps.5919

Hendrichs J, Robinson AS, Cayol JP, Enkerlin W (2002) Medfly areawide sterile insect technique programmes for prevention, suppression or eradication: the importance of mating behavior studies. Fla Entomol 85:1-13

Hendrichs J, Wornoayporn V, Katsoyannos BI, Gaggl K (1993) First field assessment of the dispersal and survival of mass reared sterile Mediterranean fruit fly males of an embryonal, temperature sensitive genetic sexing strain. In: Hendrichs J, Wornoayporn V, Katsoyannos BI, Gaggl K (eds) Management of insect pests: nuclear and related molecular and genetic techniques. International Atomic Energy Agency (IAEA), Vienna, pp 453-462

IAEA (2020) International Atomic Energy Agency. Sterile insect technique. https://www.iaea.org/topics/sterile-insect-technique (Accessed on June 2020)

Kerremans P, Franz G (1995) Use of a temperature-sensitive lethal mutation strain of medfly (Ceratitis capitata) for the suppression of pest populations. Theor Appl Genet 90:511-518

Kerremans P, Franz G (1994) Cytogenetic analysis of chromosome 5 from the Mediterranean fruit fly, Ceratitis capitata. Chromosoma 103:142-146

Kim D, Langmead B, Salzberg SL (2015) HISAT: a fast spliced aligner with low memory requirements. Nat Methods 12:357-360

Knipling EF (1955) Possibilities of insect control or eradication through the use of sexually sterile males. J Econ Entomol 48:459-462

Kunkel MT, Johnstone DB, Thomas JH, Salkoff L (2000) Mutants of a temperature-sensitive two-P domain potassium channel. J Neurosci 20:7517-7524

Lanzavecchia SB, Cladera JL, Faccio P et al (2008) Origin and distribution of Ceratitis capitata mitochondrial DNA haplotypes in Argentina. Ann Entomol Soc Am 101:627-638

Li H (2011) A statistical framework for SNP calling, mutation discovery, association mapping and population genetical parameter estimation from sequencing data. Bioinformatics 27:2987-2993

Li H, Handsaker B, Wysoker A et al (2009) The sequence alignment/ map format and SAMtools. Bioinformatics 25:2078-2079. https ://doi.org/10.1093/bioinformatics/btp352 
Liquido NJ, Cunningham RT, Nakagawa A (1990) Host plants of Mediterranean fruit fly (Diptera: Tephritidae) on the island of Hawaii (1949-1985 Survey). J Econ Entomol 83:1863-1878

Magaña C, Hernández-Crespo P, Ortego F, Castañera P (2007) Resistance to malathion in field populations of Ceratitis capitata. J Econ Entomol 100:1836-1843

Malacrida A, Gomulski L, Bonizzoni M et al (2007) Globalization and fruitfly invasion and expansion: the medfly paradigm. Genetica 131:1-9

Mellado L, Ros P, Arroyo M, Castillo E (1975) Genetic control of Ceratitis capitata: practical application of the sterile-insect technique (IAEA-PL-5 82/20). In: IAEA (ed) Controlling Fruit Flies by the Sterile-Insect Technique. Proceedings of a Panel and Research Co-ordination Meeting Organized by the Joint FAO/IAEA Division of Atomic Energy in Food and Agriculture. International Atomic Energy Agency (IAEA), Vienna, pp 51-66

Ministerio de Agricultura Pesca y Alimentación (2020) Registro de Productos Fitosanitarios. https://www.mapa.gob.es/es/agricultura/ temas/sanidad-vegetal/productos-fitosanitarios/registro/productos/ forexi.asp? $=0$ \&plagEfecto $=46$. Accessed June 2020

Papanicolaou A, Schetelig MF, Arensburger P et al (2016) The whole genome sequence of the Mediterranean fruit fly, Ceratitis capitata (Wiedemann), reveals insights into the biology and adaptive evolution of a highly invasive pest species. Genome Biol 17:1-31

Parker AG (2005) Mass-rearing for sterile insect release. In: Dyck VA, Hendrichs J, Robinson AS (eds) Sterile insect technique. Principles and practice in area-wide integrated pest management. Springer, Dordrecht, The Netherlands, pp 209-232

Parubrub A, Reyes R, Smallridge CJ et al (2015) Mitochondrial single nucleotide polymorphisms in Ceratitis capitata (Diptera: Tephritidae) can distinguish sterile, released flies from wild flies in various regions of the world. J Econ Entomol 108:301-306

Primo-Millo E, Alfaro-Lassala F, Argilés-Herrero R (2003) Plan de actuación contra la mosca de las frutas (Ceratitis capitata) en la Comunidad Valenciana. Phytoma España 153:127-130

Ramírez-Santos E, Rendón P, Ruiz-Montoya L et al (2017) Effect of irradiation doses on sterility and biological security in a genetically modified strain of the Mediterranean fruit fly (Diptera: Tephritidae). J Econ Entomol 110:1483-1494

Robinson AS (2005) Genetic basis of the sterile insect technique. In: Dyck VA, Hendrichs J, Robinson AS (eds) Sterile insect technique. Principles and practice in area-wide integrated pest management. Springer, Dordrecht, The Netherlands, pp 95-114

Robinson AS (2002) Genetic sexing strains in medfly, Ceratitis capitata, sterile insect technique programmes. Genetica 116:5-13
Rössler Y (1979) The genetics of the Mediterranean fruit fly: a "white pupae" mutant. Ann Entomol Soc Am 72:583-585

San Andrés V, Urbaneja A, Sabater-Muñoz B, Castañera P (2007) A novel molecular approach to assess mating success of sterile Ceratitis capitata (Diptera: Tephritidae) males in sterile insect technique programs. J Econ Entomol 100:1444-1449

Sayed WAAE (2013) Effect of gamma irradiation on Mediterranean fruit fly, Ceratitis capitata (Wiedemann) and improvement of the sterile-insect technique. Ph.D. Thesis. Cairo University

Sim SB, Ruiz-Arce R, Barr NB, Geib SM (2017) A new diagnostic resource for Ceratitis capitata strain identification based on QTL mapping. Genes Genomes Genet 7:3637-3647

Soderlund C, Bomhoff M, Nelson WM (2011) SyMAP v3.4: a turnkey synteny system with application to plant genomes. Nucleic Acids Res 39:e68

Soderlund C, Nelson W, Shoemaker A, Paterson A (2006) SyMAP: a system for discovering and viewing syntenic regions of FPC maps. Genome Res 16:1159-1168

Spanos L, Koutroumbas G, Kotsyfakis M, Louis C (2000) The mitochondrial genome of the Mediterranean fruit fly, Ceratitis capitata. Insect Mol Biol 9:139-144

The FlyBase Consortium/Berkeley Drosophila Genome Project/ Celera Genomics (2014) Drosophila melanogaster (fruit fly). GCA_000001215.4 Release 6 plus ISO1 MT. https://www.ncbi. nlm.nih.gov/genome/47?genome_assembly_id=204923

The i5k Initiative (2017) i5k: Sequencing five thousand arthropod genomes. http://i5k.github.io/. Accessed on April 2019

Tonzetich J, Lyttle TW, Carson HL (1988) Induced and natural break sites in the chromosomes of Hawaiian Drosophila. Proc Natl Acad Sci 85:1717-1721

Untergasser A, Nijveen H, Rao X et al (2007) Primer3Plus, an enhanced web interface to Primer3. Nucleic Acids Res 35:71-74

Zacharopoulou A, Augustinos AA, Drosopoulou E et al (2017) A review of more than 30 years of cytogenetic studies of Tephritidae in support of sterile insect technique and global trade. Entomol Exp Appl 164:204-225

Publisher's Note Springer Nature remains neutral with regard to jurisdictional claims in published maps and institutional affiliations. 